\title{
ST-SEGMENT DEPRESSION IS AN IMPORTANT INDEX OF CARDIOVASCULAR FUNCTIONAL STATE DURING EXERCISING IN NON-ATHLETES' COHORT
}

\author{
Jonas Poderys, Eugenijus Trinkūnas, Kristina Poderienè, Alfonsas Buliuolis \\ Lithuanian Sports University, Kaunas, Lithuania
}

\begin{abstract}
Research background. The hypothesis for this study was that functional ischemic episodes in cardiac muscle during intensive exercising are characteristic of non-athletes and research aim was to find out if individual functional fitness could be revealed by registering ST-segment depression during various type of exercising.

Methods. Non-athletes and well-trained runners were involved in the study. Three separate studies (firstincreasing intensity of exercising; second - intensive exercise bout; third - continuous aerobic exercising) were performed. Twelve leads EGC were registered; heart rate (HR) and ST-segment depression were taken for analysis.

Results. Elite runners exhibited better functional fitness, i.e. were able to perform higher increase in workload, and lower HR values during the same intensity of exercising. The significant differences between cohorts were observed in the dynamics of ST-segment depression. There were no significant changes at onset of incremental exercising in both cohorts, but after reaching some intensity of exercising transient ischemic episodes were registered in the cohort of non-athletes (the first study). The same type of differences between cohorts was observed at onset of maximal vertical jumping (the second study) and even during the performance of continuous aerobic exercising (the third study).

Conclusions. Functional ischemic episodes in cardiac muscle during exercising is characteristic of non-athletes but not of well-trained athletes, and the ST-segment depression could be used as an important index of ECG in the formation of feedback about exercise dosage control during health promotion exercising.
\end{abstract}

Keywords: monitoring, heart rate, ST-segment depression.

\section{INTRODUCTION}

$\mathrm{M}$ odern lifestyle, passive office work and a fast-food culture has caused the increase of health issues such as overweight, stress, sleeping problems. Protective effects of exercising are well-known. Exercises are widely used as one of the most powerful non-pharmacological strategies that affect most cells and organs in the body (Shalaby, Saad, Akar, Reda, \& Shalgham, 2012). The problem of individualization, i.e. exercise dosage control, is a talking point and this problem needs new solutions. To this day, the heart rate (HR) response measurement as a convenient non-invasive evaluation tool is widely used to monitor and analyze individual workouts (Dellal et al., 2012; Hetting, Monden, van Meeteren, \& Daanen, 2014; Jeukendrup \& VanDiemen, 1998). Various types of heart rate monitors have been used for over 30 years (Achten \& Jeukendrup, 2003). On the other hand, fast development of new technologies allows registering and monitoring a lot of new physiological parameters during exercising and it is very important to know what parameters should be included and implemented in new monitoring systems enabling objective assessment of an individual's functional state and peculiarities of their changes during exercising. Registrations of electrocardiogram (ECG) are widely used for diagnostic or functional state assessments and 
at present the abilities to register the ECG signal during exercising and transmit it by using a wireless technology became a reality. The hypothesis for this study was that functional ischemic episodes in cardiac muscle during intensive exercising is characteristic of non-athletes and the objective of this study was to establish if individual functional fitness could be revealed by registering ST-segment depression during various type of exercising.

\section{METHODS}

Three separate studies were performed as to find out peculiarities in the dynamics of HR and ST-segment depression during various types of exercising in non-athletes' and well-trained runners' cohorts. Healthy adult male non-athletes and well-trained runners took part in all these studies. These studies were approved by the Ethics Committee of the Lithuanian University of Health Sciences (No. BEC-SRFO (M)-87. 31-12-2012) and conducted in accordance with the principles outlined in the Declaration of Helsinki. All subjects provided their written informed consent before participation in the study.

A computerized system "Kaunas-load" was applied for 12 lead ECG recording and analysis while the averaged figures obtained during $10 \mathrm{~s}$ interval of all 12-leads of ECG were presented. The changes in RR interval or heart rate (HR) and STsegment depression (sum of negative values in 12 leads) were taken for analysis.

The first study was designed to compare the dynamics of chosen cardiovascular indices in conditions of increasing intensity of exercising. Participants were non-athletes $(n=21$, age $23.0 \pm 1$ years, body mass index $24.4 \pm 1.3)$ and runners $(n=$ 8 , age $20.9 \pm 1.21$, body mass index $22.3 \pm 0.38$ ) underwent a $50 \mathrm{~W}$ increase in workload (bicycle ergometry) every 6 minutes and they exercised until inability to continue the task.

The second study was designed to establish the dynamics of indices while performing intensive exercise bout. Participants were non-athletes, i.e. volunteer male students who were not engaged in sports training ( $n=11$, age $20.9 \pm 1.2$ years, body mass index $22.3 \pm 0.4)$ and runners $(n=8$, age $20.9 \pm 1.2$, body mass index $22.3 \pm 0.38$ ) underwent a 30 -second all-out repeated jumps test. The jumps were performed on a force platform. In order to prevent venous pooling, the subjects underwent $10 \mathrm{~s}$ squats after finishing the jumps and sat still during the next 3 minutes of the recovery.
The third study had to establish the peculiarities in the dynamics of indices while performing continuous aerobic exercising. Participants were non-athletes $(n=10$, age $23.3 \pm$ 0.9 years, body mass index $21.2 \pm 0.5$ ) and runners $(n=10$, age $23.1 \pm 1.3$, body mass index $21.9 \pm$ 0.4). After 5 min warm-up they had $24 \mathrm{~min}$ aerobic exercising (on a bicycle). The intensity of exercising at the beginning was chosen individually as the HR should be in the zone of $70-85 \%$ of $\mathrm{HR}_{\text {Reserve }}$. This chosen mechanical intensity (external workload) was the same during the workout.

Statistics. The arithmetic mean (x) and standard deviation (s) were calculated. The significance of the differences between values was evaluated by computing $t$ criterion; the pair's $t$-test was used. The difference was considered statistically significant when $p$ was $<.05$ (95 CI).

\section{RESULTS}

The first study (increasing intensity of exercising). The results obtained during the first study showed a significant difference between groups in physical working capacity. Non-athletes were able to continue exercising up to $250 \mathrm{~W}$, and runners continued exercising up to $350 \mathrm{~W}$. The mobilization of cardiovascular function according to HR changes during the increasing workload is shown in Figure 1. A significant increase in HR was observed during the graded exercise test up to inability to continue the task, and this increase continued according to the increasing workload. The runners' HR was significantly $(p<.01)$ lower at rest and during the entire test than that of nonathletes (before the load at rest it was $87.8 \pm 2.7$ in the group of non-athletes and $71.4 \pm 2.5$ in the runners' cohort; at the last minute of workload it was $174.3 \pm 3.0$ in the non-athletes' cohort and $166.7 \pm 3.4$ in the endurance cohort). The study showed that athletes demonstrated higher physical performance but maximal HR values were in both cohorts when the full fatigue phase was achieved, and these values did not differ significantly $(p>.05)$. Faster HR recovery was observed in the group of runners.

Different type of dynamics of ST-segment depression in runners' and non-athletes' cohorts was discovered during incremental exercising. There was no significant change observed in runners' cohort while other type of dynamics was observed in non-athletes' cohort. There was no change in ST-segment depression at onset of 
Figure 1. Dynamics of $\mathbf{H R}$ and ST-segment depression during the incremental increase in workload and recovery

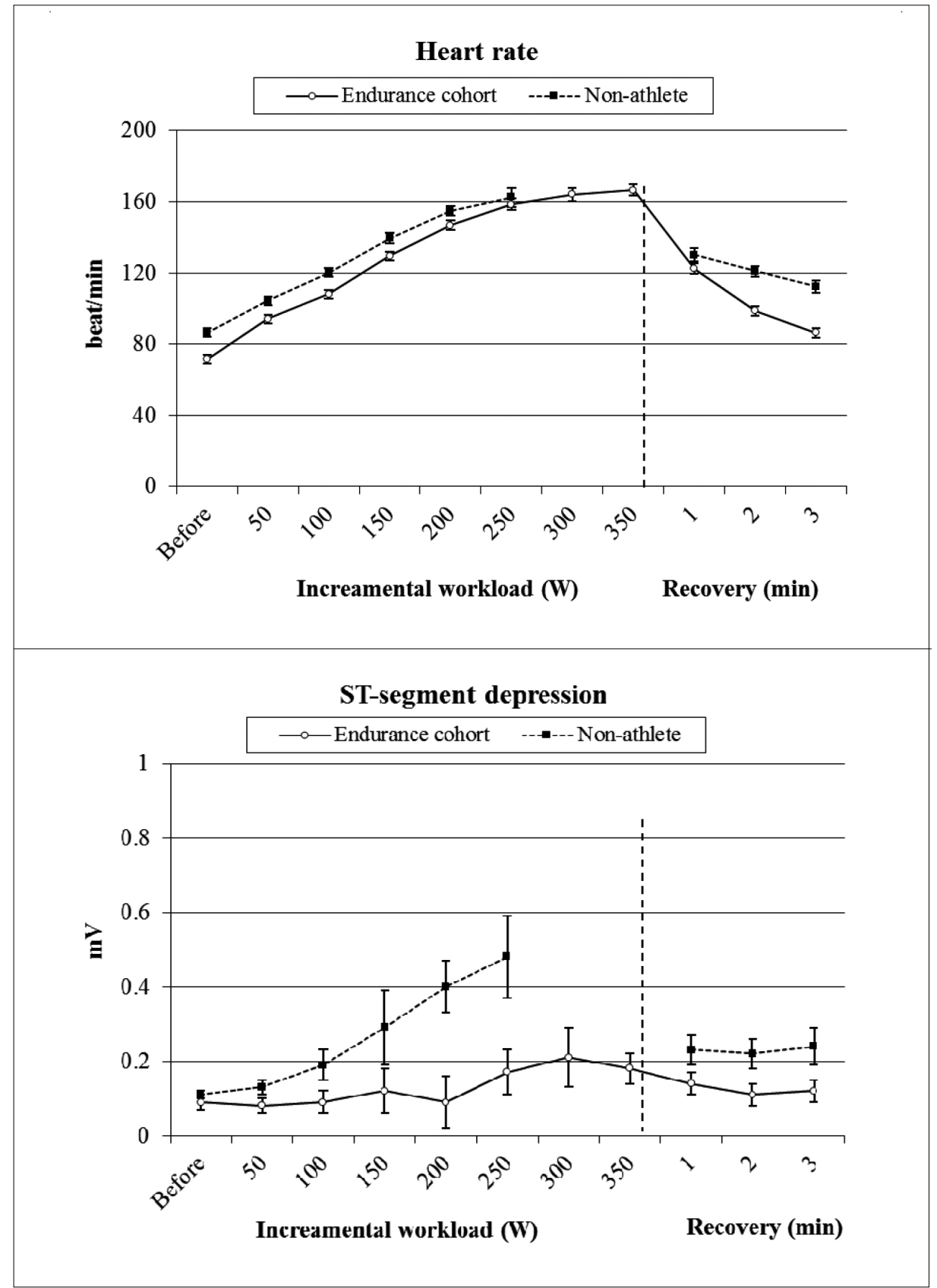

exercising, but when the intensity of exercising increased the individual type of change was observed. The averaged data presented in Figure 1 showed an increase of ST-segment depression while the intensity of exercising was $100 \mathrm{~W}$, and further increase with each step of increasing workload in the non-athletes' cohort. During the highest physical test loads in both groups, the difference between the cohorts was statistically significant, $p<.05$ (in non-athletes' cohort it was recorded at $250 \mathrm{~W}$, ST-segment depression $-0.48 \pm$ $0.11 \mathrm{mV}$; in runners' cohort - at $350 \mathrm{~W}-0.18 \pm 0.02$ $\mathrm{mV}$ ST-segment depression).

The second study (intensive exercise bout). At onset of repeated maximal jumps, a steep change of cardiovascular indices occurred. Figure 2 presents the dynamics of registered ECG indices when performing a 30 -s repeated jump test and during the recovery. The same type of changes in HR, i.e. steep increase, was observed in both cohorts. The HR at the end of jumping task was $168.4 \pm 2.2$ beats/min in runners' cohort and $174.5 \pm 2.2$ beats/ min in non-athletes' cohort. Different dynamics of ST-segment depression during the intensive jumping task was observed. There was a small change found in runner's cohort, but the significant $(p<.05)$ increase of ST-segment depression was observed in non-athletes' cohort (the sum of negative values in 12 leads was $0.85 \pm 0.32 \mathrm{mV}$ ). 


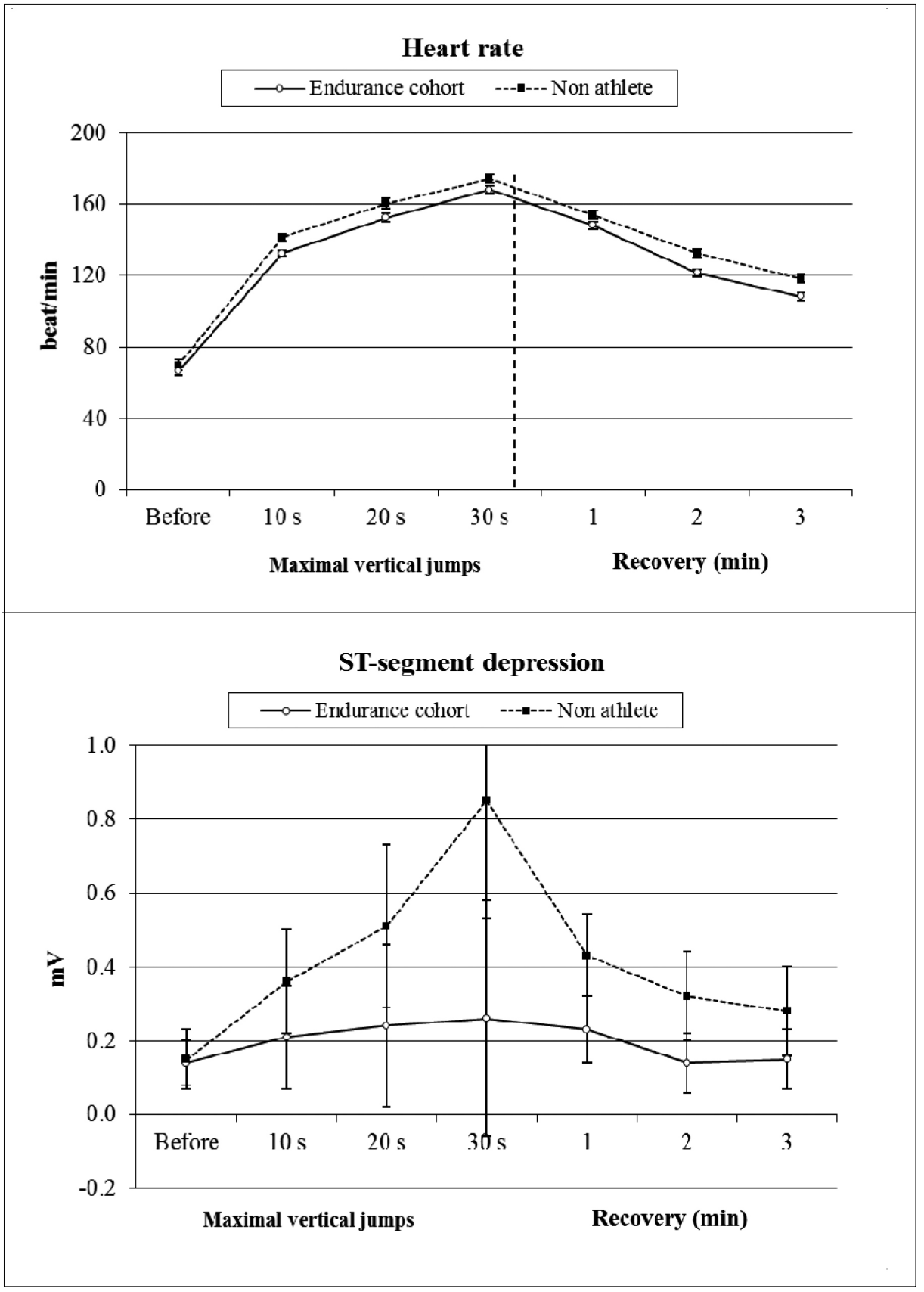

Figure 2. Dynamics of HR (A) and ST-segment depression during the 30-s vertical jumps test and recovery

The third study (continuous aerobic exercising). The results obtained during this study showed significant difference in functional fitness of participants and their ability to perform the external workload. The influence or regular training of runners became evident while comparing the intensity of exercising. The averaged values of relative power during exercising were $1.9 \pm 0.1 \mathrm{~W} / \mathrm{kg}$ of body weight in runners' cohort and $1.5 \pm 0.1 \mathrm{~W} /$ $\mathrm{kg}$ of body weight in non-athletes' cohort $(p<.05)$.

Figure 3 presents the dynamics of HR and ST-segment depression during continuous aerobic exercising. There were no significant differences between the groups in HR at onset of exercising, but the steepest increase of HR was observed in non-athletes' cohort.

Different types of dynamics of ST-segment depression were registered during continuous aerobic exercising. Figure 3 shows that there were no significant changes of ST-segment depression during exercising in runner's cohort $(p>.05)$, and the significant increase of ST-segment depression was in non-athletes' cohort $(p<.05)$. It should be noted that some individuals from non-athletes' cohort did not demonstrate significant changes, but averaged values of ST-segment depression (the sum of negative values in 12 leads) were $0.37 \pm 0.07 \mathrm{mV}$ at onset of exercising and slightly decreased at the end of exercising $(0.32 \pm 0.07 \mathrm{mV})$. 
Figure 3. Dynamics of $\mathbf{H R}$ and ST-segment depression during the continuous aerobic exercising and recovery

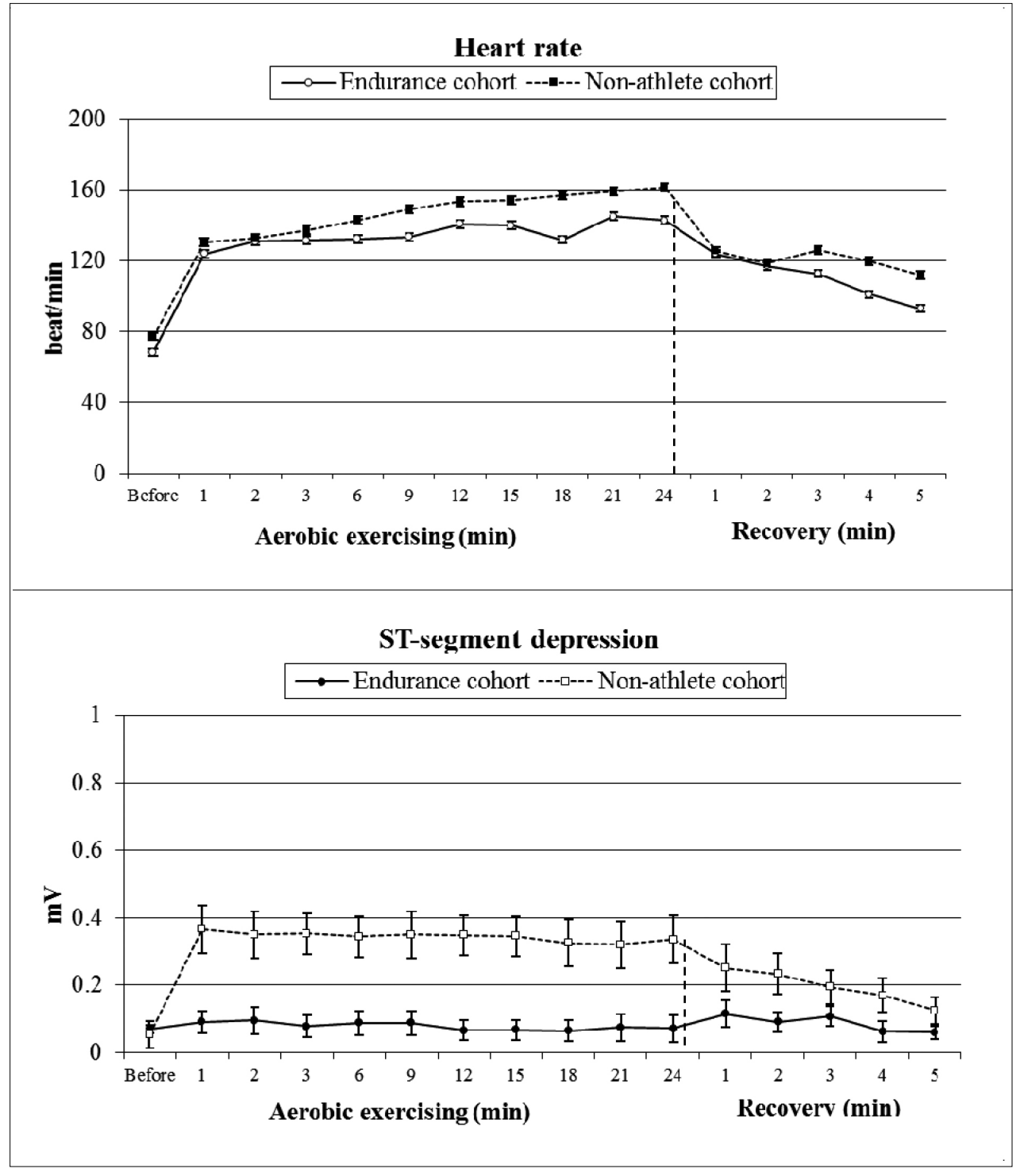

\section{DISCUSSION}

Exercising positively affects body functions and individualization in this case is a key point for success. The fast development of new technologies allows registering and monitoring ECG signals during exercising and the question is what kind of indices can be added to monitoring HR as to provide valuable information. The analysis of cardiac response to various types of exercising could be helpful here.

There is no doubt that endurance athletes demonstrate higher performance abilities than non-athletes. This was shown by many researchers (Buliuolis, Trinkūnas, Snarskaite,, \& Poderys, 2003; Cantrell, Schilling, Paquette, \& Murlasits, 2014; Delp, 1998; Noakes, 2000; Noakes, Peltonen, \& Rusko, 2001; Poderys, 2002) noting that the improvement is a result of changes in many body systems and mostly it occurs by adaptation of cardiovascular system. This observation was confirmed in our first study. The results showed that athletes differed from the healthy group with better cardiovascular reactions to incremental increase in workload. The comparison showed that elite runners exhibited better functional fitness; the increasing workload HR values were significantly lower in well-trained runners than in the cohort of non-athletes. The lower HR values at various steps of increasing workload indicate higher functional abilities that were obtained by training.

There were no ischemic episodes at onset of incremental exercising in both cohorts at onset of exercising, but after reaching some intensity transient ischemic episodes were registered in the cohort of non-athletes. The same type of differences between cohorts was observed at onset of jumping (the second study) and even during the 
performance of continuous aerobic exercising (the third study). Prognostic importance of ischemic episodes detected by ST-segment monitoring has been shown in many investigations (Guldenring et al., 2012; Yazigi et al., 1998; Jernberg, Lindahl, \& Wallentin, 1999; Taglieri et al., 2011).The transient increase in ST-segment depression during exercising indicates ischemic episodes in cardiac musculature that could be treated as heart function limiting failure during the load, which this is not a desirable physiological change.

The cardiovascular system is one of the constituent parts and a holistic system of the body (Pande et al., 2012, van Schuylenbergh, Eynde, \& Hespel, 2004; Vainoras, 2002). By summarizing the results obtained during these studies it should be noted that the cardiovascular system with its functional adaptation to workloads is an important factor defining the peculiarities of their response to exercising. There were no serious functional ischemic episodes found in cardiac musculature during various types of exercising in welltrained athletes' cohorts, but it was common in non-athletes' cohorts. This is an important point for monitoring cardiovascular response during exercising. ST-segment depression could be a valuable marker testifying individual limits.

\section{CONCLUSION}

Functional ischemic episodes in cardiac muscle during exercising is a characteristic of nonathletes, but not of well-trained athletes, and the ST-segment depression could be used as important index of ECG in the formation of feedback about exercise dosage control during health promotion exercising.

Acknowledgement. This research has been supported by ITEA 2 Programme, Project CareWare, No 13034.

\section{REFERENCES}

Achten, J., \& Jeukendrup, A. E. (2003). Heart rate monitoring: Applications and limitations. Sports Medicine. 33(7), 517-538. Retrieved from http://www. ncbi.nlm.nih.gov/pubmed/12762827

Buliuolis, A., Trinkūnas, E., Snarskaitè, R., \& Poderys J. (2003). Didelio meistriškumo sportininkų ir nesportuojančių asmenų širdies ir kraujagyslių sistemos funkcinès būklès kaita atliekant aerobinius ir anaerobinius krūvius (Functional state of cardiovascular system in high skilled athletes and non-athletes in performing of aerobic and anaerobic loads). Sporto Mokslas, 1(31), 56-61.

Cantrell, G. S., Schilling, B. K., Paquette, M. R., \& Murlasits, Z. (2014). Maximal strength, power, and aerobic endurance adaptations to concurrent strength and sprint interval training. European Journal of Applied Physiology, 114(4), 763-771. doi: 10.1007/s00421-0132811-8.

Dellal, A., Owen, A., Wong, D. P., Krustrup, P., van Exsel, M., \& Mallo, J. (2012). Technical and physical demands of small vs. large sided games in relation to playing position in elite soccer. Human Movement Science, 31(4), 957-969. doi: 10.1016/j. humov.2011.08.013. Retrieved from http://www.ncbi. nlm.nih.gov/pubmed/22341858

Delp, M. D. (1998). Differential effects of training on the control of skeletal muscle perfusion. Medicine and Science in Sports and Exercise, 30(3), 361374. Retrieved from http://www.ncbi.nlm.nih.gov/ pubmed/9526881

Guldenring, D., Finlay, D. D, Nelwan, S. P., Nugent, C. D., Donnelly, M. P., \& Bond, R. R. (2012). Es- timation performance of a reduced lead system during continuous 12-lead ECG ST-segment monitoring. Journal of Electrocardiology, 45(6), 604-608. doi: 10.1016/j. jelectrocard.2012.08.012. Retrieved from http://www. ncbi.nlm.nih.gov/pubmed/23022301

Hetting, F. J., Monden, P. G., van Meeteren, N. L., \& Daanen, H. A. (2014). Cardiac acceleration at the onset of exercise: A potential parameter for monitoring progress during physical training in sports and rehabilitation. Sports Medicine, 44(5), 591-602. doi: 10.1007/s40279013-0141-y. Retrieved from http://www.ncbi.nlm.nih. gov/pubmed/24469736

Jernberg, T., Lindahl, B., \& Wallentin, L. (1999). STsegment monitoring with continuous 12-lead ECG improves early risk stratification in patients with chest pain and ECG nondiagnostic of acute myocardial infarction. Journal of the American College of Cardiology, 34(5), 1413-1419. Retrieved from http://www.sciencedirect. com/science/article/pii/S0735109799003708

Jeukendrup, A., \& VanDiemen, A. (1998). Heart rate monitoring during training and competition in cyclists. Journal of Sports Sciences, 16, S91-99. doi: 10.1080/026404198366722. Retrieved from http:// www.ncbi.nlm.nih.gov/pubmed/22587722

Noakes, T. D. (2000). Physiological models to understand exercise fatigue and the adaptations that predict or enhance athletic performance. Scandinavian journal of Medicine and Science in Sports, 10(3), 123-145. Retrieved from http://www.ncbi.nlm.nih.gov/ pubmed/10843507

Noakes, T. D., Peltonen, J. E, \& Rusko, H. K. (2001). Evidence that a central governor regulates exercise performance during acute hypoxia and hyperoxia. The 
Journal of Experimental Biology, 204(Pt 18), 32253234. Retrieved from http://www.ncbi.nlm.nih.gov/ pubmed/11581338

Pande, S. S., Pande, S. R., Dhore, R. B., Daphale, A. V., Parate, V. R., Patel, S. S., \& Agrekar, S. H. (2012). Assessment of cardiovascular response to treadmill exercise in normal healthy Indian adolescents. Indian Journal of Physiology and Pharmacology, 56(1), 36-41. Retrieved from http://www.ncbi.nlm.nih.gov/ pubmed/23029962

Poderys J. (2002). Acute and chronic adaptation of cardiovascular function to sprint or endurance training. Education. Physical Training. Sport, 3, 44-48.

van Schuylenbergh, R., Eynde, B. V., \& Hespel, P. (2004). Prediction of sprint triathlon performance from laboratory tests. European Journal of Applied Physiology and Occupational Physiology, 91(1), 94-99. Retrieved from http://www.ncbi.nlm.nih.gov/pubmed/12955517

Shalaby, M. N., Saad, M., Akar, S., Reda, M. A., \& Shalgham, A. (2012). The Role of Aerobic and Anaerobic
Training Programs on $\mathrm{CD}(34+)$ Stem Cells and Chosen Physiological Variables. Journal of Human Kinetics, 35, 69-79. doi: 10.2478/v10078-012-0080-y. Retrieved from http://www.ncbi.nlm.nih.gov/pubmed/23486555

Taglieri, N., Marzocchi, A., Saia, F., Marrozzini, C., Palmerini, T., Ortolani, P., Rapezzi, C. (2011). Shortand long-term prognostic significance of ST-segment elevation in lead aVR in patients with non-ST-segment elevation acute coronary syndrome. The American Journal of Cardiology, 108(1), 21-28. doi: 10.1016/j. amjcard.2011.02.341. Retrieved from http://www.ncbi. nlm.nih.gov/pubmed/21529728

Vainoras A. (2002). Functional model of human organism reaction to load evaluation of sportsmen training effect. Education. Physical Training. Sport, 44, 88-93.

Yazigi, A., Richa, F., Gebara, S., Haddad, F., Hayek, G., \& Antakly, M, C. (1998). Prognostic importance of automated ST-segment monitoring after coronary artery bypass graft surgery. Acta Anaesthesiologica Scandinavica, 42(5), 532-535. 